\title{
Diversification in the international construction business
}

Article

Accepted Version

Ye, M., Lu, W., Flanagan, R. and Ye, K. (2018) Diversification in the international construction business. Construction Management and Economics, 36 (6). pp. 348-361. ISSN 1466433X doi: https://doi.org/10.1080/01446193.2017.1388530 Available at https://centaur.reading.ac.uk/73409/

It is advisable to refer to the publisher's version if you intend to cite from the work. See Guidance on citing.

To link to this article DOI: http://dx.doi.org/10.1080/01446193.2017.1388530

Publisher: Informa UK Limited

All outputs in CentAUR are protected by Intellectual Property Rights law, including copyright law. Copyright and IPR is retained by the creators or other copyright holders. Terms and conditions for use of this material are defined in the End User Agreement.

\section{www.reading.ac.uk/centaur}

\section{CentAUR}

Central Archive at the University of Reading

Reading's research outputs online 


\title{
Diversification in the international construction business
}

\author{
Meng $\mathrm{Ye}^{1}$, Weisheng $\mathrm{Lu}^{2}$, Roger Flanagan ${ }^{3}$, and Kunhui $\mathrm{Ye}^{4}$
}

\begin{abstract}
Economic globalisation has created an interdependent market that allows companies to transcend traditional national boundaries to conduct business overseas. In the international construction market, companies often adopt diversification as a strategy for growth, for risk management, or for both. However, the diversification patterns of international construction companies (ICCs) as a group are barely clear. The primary aim of this research is to cover this knowledge void by mapping ICCs' diversification patterns in both business sectors and geographical dispersal. It starts from a literature review of diversification theories. Based on the review, a series of propositions relating to ICCs' diversification are proposed. Data is gleaned from Engineering News-Record and database i.e. Bloomberg and Capital IQ, ranging from 2001 to 2015. By testing the hypotheses, it is found that larger ICCs prefer to diversify than their smaller counterparts. Most of the ICCs tend to diversify to geographical markets with similar cultural or institutional environment. Market demands drive ICCs to diversify to different geographical markets while they are more prudential in venturing into new business sectors. The research provides not only valuable insights into diversification patterns of ICCs, but also a solid point of departure for future theoretical and empirical studies.
\end{abstract}

Keywords: International construction, Diversification, Entropy, Competitive strategy, Strategic management

\footnotetext{
${ }^{1} \mathrm{Ph}$. D. Candidate, Dept. of Real Estate and Construction, Faculty of Architecture, Univ. of Hong Kong, Pokfulam, Hong Kong (corresponding author). E-mail: megan828@hku.hk, Tel: +8526704 4695.

${ }^{2}$ Associate Professor, Dept. of Real Estate and Construction, Faculty of Architecture, Univ. of Hong Kong, Pokfulam, Hong Kong. E-mail: wilsonlu@ @ku.hk, Tel: +852 28597981.

${ }^{3}$ Professor, School of Construction Management and Engineering, Univ. of Reading, Reading RG6 6AW, U.K. E-mail: r.flanagan@ reading.ac.uk, Tel: +44 (0) 1183788594.

${ }^{4}$ Professor, Faculty of Construction Management and Real Estate, Chongqing Univ., Chongqing 400045, China. E-mail: Kunhui_Ye@cqu.edu.cn,
} 


\section{Introduction}

Diversification (Ansoff 1957) is a departure from a firm's previous experience base (Kim and Reinschmidt 2011a). Over the past decades, diversification has become an important component of a firm's strategic management (Palepu 1985). The resource-based view (RBV) of firms provides one explanation of the motivation to diversify. As a firm gathers resources for one business, it may maintain excess capacity over time that can be sufficiently scalable for use in other product lines or markets and some of them (Lowe and Teece 2001). It is the excess capacity, coupled with profitseeking motivation that drive the decisions to diversify. Risk management is another motivation for firms to diversify. According to Rubinstein (2002), diversification is a way to reduce risk. Riskaverse investors desire to be and are expected to diversify.

In the construction sector, companies also adopt diversification as a strategy for either growth, or risk management, or both (Kim and Reinschmidt 2011b). However, construction has its own heterogeneity, which can be perceived from four aspects: the physical nature of outputs; the structure of the industry, together with the organisation of the construction process; the determinants of demand; and the method of price determination (Hillebrandt 2000). All these characteristics can be shared separately by other industries but in combination appear in construction alone (Hillebrandt 2000). The heterogeneity of construction business may lead to totally different diversification strategies and in turn, diversification patterns.

There is a limited but growing body of literature exploring diversification strategies in the construction sector. Choi and Russell (2005) investigated the long-term effects of diversification strategies on profitability change of U.S. public construction firms. Kim and Reinschmidt (2011b) performed an empirical analysis of diversification strategies by the largest U.S. contractors. They mapped the diversification patterns by these contractors, seeking to understand the possible 
reasons for diversification, and exploring the difference in firm performance caused by diversification. Kim and Reinschmidt (2011a) associated contractors' organisational risk attitudes with their diversification strategies to help understand the reasons for their competitive success. Abdul-Aziz and Abdul-Rashid (1994) asserted that to remain competitive construction firms need to be lean by concentrating on the areas that they are best equipped to deal with. However, Anand and Singh (1997) argued that focused firms, as compared to diversified firms, are more likely to be vulnerable to the vicissitudes of individual markets. Using empirical evidence, Kale and Arditi (2002) reported that companies in the U.S. construction market tend to adopt a neutral approach to the scope of competition to outperform their rivals. Jewell et al. (2014) explored construction professional services firms' dilemma of diversification and focus, represented by business scope and scale in their writing.

Notwithstanding the aforementioned studies, diversification in international construction has rarely been explored. "International construction" is when a construction company resident in one country performs work in another country (Ngowi et al. 2005). Readers may have also encountered the concept of "global construction", which includes both domestic and international market. According to Global Construction Perspectives and Oxford Economics (2015), the global construction market is set to grow by US\$8 trillion by 2030 , reaching a total size of US\$ 17.5 trillion, up by $85 \%$ and growing by an average annual rate of $3.9 \%$ to 2030 . Unlike the traditional image that construction is seen as a local business predominantly using local people, skills, and materials, many of today's firms operate globally outside their home countries. In the context of globalization and the open market, the construction industry and construction activities have inevitably been affected by external factors over the past decades (Liu and Zhu 2017). Economic globalisation, advanced technology, fast transportation, convenient communications, effective 
knowledge transfer, integrated markets, and trade liberalisation have all helped the construction business traverse traditional national boundaries into the international arena (Lu et al. 2013, Lu et al. 2014). Diversification is one of the most preferred strategies for construction companies to enhance their competitive advantages to survive and thrive in this international market. However, there is a paucity of understanding of diversification in the international market.

The primary aim of this research is to investigate diversification patterns as contributed by companies in international construction business by means of measurement, mapping, visualisation and analyses. The research can not only portray a clear picture of international construction companies' (ICCs') diversification patterns, but also provide findings, based on which further research could be explored, such as motivations of diversification, institutional impacts on international diversification, and implications of diversification on corporate financial performance. The remainder of this paper is structured as follows. The next section, Section 2, provides the theoretical basis. The heterogeneity of international construction business would be presented in Section 3. Section 4 is to develop the hypotheses to allow the diversification patterns to be portrayed. Section 5 describes the methods that involve selecting sample and data, deliberating the diversification measurement, and adopting the diversity index based on entropy. Section 6 reports the analyses and results, while Section 7 provides an in-depth discussion to strengthen the understanding of both. Conclusions are drawn in Section 8 together with limitations and suggestions for further related research.

\section{Theories}

The term "diversification" as a business strategy was coined by the management guru Ansoff (1957). It has been so well mainstreamed that the term is almost self-explanatory without requiring 
further scholar definitions. For example, diversification is "a corporate strategy to enter a new market or industry which the business is not currently in" (Ross et al. 1993); it is a departure from a firm's previous business experiences (Kim and Reinschmidt 2011a) and is one way to spread the base of a business (Booz et al. 1985); none of them sounds like scholarly well-defined. There are different types of diversification. Ansoff (1957) proposed the typology of vertical, horizontal, and lateral diversification. Wrigley (1970) distinguished two modes of product diversification - related and unrelated diversification. Related diversification exists when a firm owns a number of different business units, all of which are related in one way or another while under unrelated diversification the firm diversifies into substantively different areas from the existing ones (Rowe and Wring 1997). There are other typologies of diversification, e.g., concentric diversification and conglomerate diversification, which are not mutually exclusive. Rather, they can be supplemented with each other to understand the rich meanings of the concept. Specific forms of diversification could be organic growth or inorganic growth, such as merger, acquisition, or alliance (Locket et al. 2009, Jewell et al. 2014).

The motivations driving firms' endeavour to diversify have also been widely discussed. In Ansoff's (1957) seminal article, he passionately summarised that "companies diversify to compensate for technological obsolescence, to distribute risk, to utilise excess productive capacity, to reinvest earnings, and to obtain top management". Diversification is a way of growth open to business (Jacquemin and Berry 1979). In Ansoff's Product/Market matrix, diversification is one of the four main growth strategies. This is supported by Arasti et al. (2010) who argued that diversification can be driven by firms' aspiration to make use of their excessive assets to enter different industries. Following Penrose's (1959) early theoretical perception that an organisation is "a collection of resources", RBV has been developed, proposing that a firm can develop its 
resources, such as core competence and technical 'know-how' to gain its competitive advantages (Barney 1991). Some excessive resources can be scaled up to develop other businesses, either related or unrelated. This is echoed by Hitt et al. (1997), who found that related diversification facilitates the sharing of activities and the transfer of skills across businesses to increase firm value. Diversification is thus regarded as one way to make full use of the surplus resources or core competence (Jewell et al. 2014). Another rationale of market diversification is for risk management (Chang and Thomas 1989). In portfolio theory, diversification is a way to reduce risk. By diversification, it can minimise the risk of over-reliance on working in a single market with a cyclical and fluctuating demands in construction (Jewell 2011). Nevertheless, while it could be used for risk management, diversification into a new market itself could be highly risky as well (Ansoff 1957).

The dilemma in diversifying to achieve business growth/risk management can also be comprehended from the economics concepts of 'economies of scope and scale', so termed and developed by Panzar and Willig $(1977,1981)$. Diversification faces the dilemma of 'economies of scope and scale' and 'ineconomies of scope and scale'. A certain level of scope and scale achieved through diversification can help cultivate benefits such as business growth, or shared operational cost. However, when the scope and scale increase to an extent in which benefits cannot offset the cost, 'ineconomies of scope and scale' would be seen. Researchers (e.g. Rowland 1999, Marshall 2015) thus also link diversification with the economics concept of transaction cost (Coase 1937, Williamson 1991) to examine the optimal degree that diversification can truly enable its potential benefits to be cultivated.

Diversification is recognised as a hallmark contribution to the strategic management literature. Diversification as a competitive strategy can be connected to Porter's $(1980,1985)$ 
theories on competitiveness, in particular, the 'focus' strategy, whereby firms can possess a competitive advantage by offering a specialised product/service to serve a niche market. At the first glance, diversification seems contradicting with the 'focus' strategy, but if linking it with the 'scope and scale' rehearsed above, they emphasise the same thing. They both emphasise the optimal scope and scale that a company are comfortable with and can manage to realise the goals of growth and/or risk management. The theoretical debates on strategic group (Hunt 1972) were developed after diversification (Ansoff 1957) and further advanced by Porter (1980, 1985). The stream of debates assumes that groups of companies within an industry have similar business models or similar combinations of strategies including diversification. Strategic groups, however, are not to be confused with Porter's competitive strategies or Ansoff's diversification, which are about internal strategies that a firm adopts.

Diversification as a business strategy has been explored in construction business but rare in an international scale. These two concepts, construction and international construction, will be elaborated in greater detail later. Economic globalisation presents both opportunities and challenges. Dunning (1979) develop the eclectic paradigm, also known as the 'Ownership, Location, and Internalisation' (OLI) model, which offers a powerful explanatory framework on international production. Hofstede (1984) developed the model of international culture difference and its consequence on work-related value. Kogut and Singh (1988) advanced the concept of 'culture distance' with a view to informing the entry mode adopted by multinational corporations (MNCs) to enter a new geographical market. Cultural distance is challenged by Bae and Salomon (2010) who argue that 'institutional distance' can better explain the entry mode. None of the theories seems monolithic in explaining the phenomenon of business diversification. Traditional theories on diversification enjoyed its vogue but also received their share of criticism in 
construction. A central argument is that these theories are developed from the old manufacturing era, therefore, they are not necessarily suitable for service industries (Low and Jiang 2003, Løwendahl 2005). Capar and Kotabe (2003) looked at diversification and performance in services, and developed a theoretical argument about their relationship, which showed a marked difference from that in manufacturing. Seymour (1987) and Low and Jiang (2003) adapted the OLI model in analysing internationalisation of MNCs in the construction industry. Chen and Messner (2005) explored the entry modes preferred by construction MNCs. Construction is increasingly listed in the service sector, although it has been often mistakenly perceived as a production sector, probably in that its outcome is similar to manufactured goods (Lu et al. 2013). Construction is even more heterogeneous than other service sectors therefore it arguably deserves special considerations when applying diversification theories (Low and Jiang 2003, Jewell and Flanagan 2012).

\section{International construction business}

Understanding diversification patterns in the international construction business needs in-depth understanding of its nature by relating to the general characteristics of the construction industry. Dainty et al. (2007) indicates that precisely what constitutes the construction industry is subject to a range of different boundary definitions. Pearce (2003) distinguishes between narrow and broad definitions of the construction sector. The former focuses on on-site assembly and the repair of buildings and infrastructure as performed by contractors. This part of business is known by many as contracting. If Pearce's broad definition is adopted, the boundary of the construction industry extends beyond on-site activity to include quarrying of raw materials, manufacture of building materials, sale of construction products, and professional services (Dainty et al. 2007). Construction professional services could include architecture, urban planning, landscape 
architecture, engineering, surveying, or even construction-related accountancy, legal, information and communication technology services, and others (Jewell et al. 2010). Lu et al. (2013) describe a typology of construction businesses, a simple version of which is shown in Fig. 1. The 4-digit U.S. SIC codes are added to define and contextualise the scope of the study; in accordance with the sectoral classification systems such as the United Nation's International Standard Industrial Classification or the U.K. Standard Industrial Classification.

$<<$ Insert Fig. 1 here >>

A construction company could diversify into any of the business sectors. It is a natural move for a contracting firm currently specialised in a business, e.g. 'General building construction' (SIC 1520), using its existing knowledge and resources, to expand to other contracting businesses such as 'Water, sewer, pipeline, communication \& power line construction' (SIC 1623) or 'Civil engineering work' (SIC 1600) (Kim and Reinschmidt 2011b, Kale and Arditi 2002). This is related diversification. To meet the growing trend towards providing 'one-stop' service, contracting firms have expanded into construction professional services (CPS), such as engineering services (SIC 8711) or architecture service (SIC 8712). Contracting firms and CPS firms often joint venture to undertake construction projects (Lu et al. 2013). Although their SIC codes (e.g. SIC 16xx and SIC 87xx) are much different, this can still be perceived as related diversification. A construction firm could even expand beyond its present business to a seemingly unrelated industry. For example, many of Australia's top contracting firms are heavily involved in mining (SIC 1000-1499). Some of China's contracting firms invest in cotton mills as parts of the agricultural business (SIC 01000999) (Lu et al. 2013). The focus of this study is related diversification in the contracting business. 
Equally intriguing, rarely explored though, is construction firms' diversification strategies in different geographical areas. Here, "geographical areas" mean overseas in different continents. In analysing international construction markets and business, there is no standard taxonomy to categorise geographical areas. Researchers tend to adopt the convention used by the $E N R$, whereby regional markets are classified into North America, Latin America, Caribbean Islands, Western/Eastern Europe, the Middle East, Asia/ Australia, North Africa, Central and Southern Africa, and Antarctic/Arctic. While U.S. and Western Europe consistently provide the largest construction markets, emerging economies such as some Asian countries, the Middle East and African areas, have growing demands in construction. Unlike other types of businesses that can create the demand for their new products or services, ICCs normally react to construction demand passively (Kim and Reinschmidt 2011b). Many large construction firms thus flow with the market demands up and down in different countries around the world.

\section{Hypotheses}

To refresh, the aim of this research is to portray the diversification patterns of ICCs. Drawing upon the strategic group analysis and the characteristics of international construction business as elaborated above, it would be intuitive to assume that ICCs are not a homogeneous group in terms of diversification strategies. Rather, they will present different diversification patterns and can be clustered into different groups for analyses. This leads to the first hypothesis of this study:

$H_{1}$ : International construction companies (ICCs) present different strategic groups in adopting diversification strategies in the international construction market.

Diversification has been adopted by firms to utilise their excess production capacity (Ansoff 1957). Company size, measured by employees on the payroll and the volume of international 
revenues, is used as a surrogate of firms' service/production capacity. Jewell et al. (2014) pointed out that properly accrued, the higher the annual revenue of the firm (or the larger the number of employees), the greater the ability to offer clients more services, and the greater the opportunity to grow; and in turn, growth can help to rationalise operating costs, thus enabling the firm to become more competitive and so win more projects, increasing annual revenue and profits. It is thus hypothesised:

$\mathrm{H}_{2}$ : ICCs with larger firm sizes are likely more diversified than their smaller counterparts in the international construction market.

In international business, where to diversify is interested by researchers and strategists. This is evident in the abundant research on entry mode (e.g. Chen and Messner 2005), which is to describe specific diversification strategies, and the research on OLI theory (Dunning 1979) or culture/institutional distance (e.g. Kogut and Singh 1988, Bae and Salomon 2010), which aims to provide an explanatory framework to different diversification strategies. Traditionally, construction business, particularly in the international market, is subject to many different regulations, such as controls on land use; building regulations and technical requirements; and environmental regulations (World Trade Organization [WTO] 1998). These institutional hurdles have been much lowered owing to economic globalisation, the widespread acceptance of the General Agreement on Tariffs and Trade in particular. However, these regulations are still found to be onerous to international construction business. It would be reasonable to hypothesise that ICCs select geographical markets with shorter culture/institutional distance to diverse, unless there are unique institutional arrangements, such as U.S. firms in the Middle East (e.g., powerful political influence) or Chinese firms in Africa (e.g. with historical and long-term relationships): 
$H_{3}$ : ICCs are more likely to select geographical markets with shorter culture/institutional distance to diversify into.

Based on above literature review, it became clearer that diversification itself will bring new risks to the firms, although it is often used as a risk management strategy. A combination of the two dilemmatic forces would drive ICCs to adopt a prudential position. This position may be particularly held in view of the considerations of 'economies of scope and scale' and 'ineconomies of scope and scale' (Panzar and Willig 1977, 1981) or the 'focus' strategy (Porter 1980, 1985). Putting these considerations into context, there are two dimensions for ICCs to diverse including (a) business sectors, and (b) geographic markets in the international construction business. Intuitively, it is hypothesised:

H4: ICCs diversify widely in either business sectors or geographic markets but not in both dimensions simultaneously

\section{Methods}

\subsection{Sample and data}

Engineering News-Record (ENR) has published annual revenue data about contracting firms in the U.S. and some other international markets since 1958. The Top 225 International Contractors (TIC 225) list, which was changed to the Top 250 International Contractors [TIC 250] list in 2013 due to the increasing number of ICCs, are selected as the representative of international contracting firms for two reasons. First, as Ye et al. (2009) found, contractors other than the TIC 225/250 have negligible power in the international market, as their market shares are relatively very small. Second, that although slight discrepancies were found, ENR data on the TIC 225/250 can be confidently used for international construction research (Lu 2014). These lists compiled annually show the top 225/250 international contractors' international revenues (revenues outside their 
domestic markets), total revenues (global revenues), new contract awards, and previous year's ranking. All the revenues are on the basis of the contractors' previous year financial performance, e.g. the revenues reported in TIC 225 in 2009 are based on the contractors' revenues generated in 2008.

Since 2001, the ENR has classified contracting business into nine sectors: general building (GB), transportation (TRAN), manufacturing (MFG), power (PW), water supply (WS), sewerage/solid waste (SW), industrial process/petroleum (IPP), hazardous waste (HW), and telecommunications (TC). The data sets provide the firms' percentage of international revenues in each sector. If the sum of the percentage of a firm is less than $100 \%$, it is explained that other kinds of non-contracting business contribute to its international revenue. Therefore, the ENR provides good data to analyse business diversification in different sectors.

Likewise, the ENR has classified contracting business into nine regional markets: North America (A), Latin America (B), Caribbean Islands (C), Europe (D), the Middle East (E), Asia/ Australia (F), North Africa (G), Central and Southern Africa (H), and Antarctic/Arctic (I). Few contractors operating in the Caribbean Islands (C) because of the size of the market. Revenues from Africa are reported as one continent, $\mathrm{G}$ and $\mathrm{H}$ are thus combined to one. As a result, six regional markets are adopted to analyse geographical diversification patterns.

The firms in the TIC 225/250 list are not static but change each year, depending on their international revenues. Some firms drop off the lists in certain years. The TIC 225/250 lists from 2001 to 2015 were collected and collated in an MS Excel file. Some of the companies, mostly ranked at the bottom of the list, appeared with erratic data, they were therefore excluded for the purposes of this research. This left the ENR top 100 international contractors, whose revenues from different regions were collected from companies' financial reports and databases such as 
Bloomberg and Capital IQ. Not all the contractors report their international revenues in each regional market. As a result, 49 out of 100 ICCs who provide both business diversification data and geographical diversification data are selected for the analysis. Not all the ICCs provide the data for the entire 15 years, the average length of the data for the 49 firms is 9.82 years. This gives us 481 observations, which form an acceptable basis to examine diversification patterns in the international construction markets over time.

\subsection{Measurement}

Unlike many other concepts in the management field, diversification appears to be amenable to quantitative measurement, e.g. using a diversity indexes (DI). Various measures of firm diversification have been developed. Three measures are most used: concentration ratio, Herfindahl index, and entropy measure. These measures are also commonly seen in industrial economics (e.g., Bird 1999, McCloughan 2004, Ye et al. 2009), particularly in measuring market concentration. Concentration is about structure of a business sector, e.g. the whole construction industry, while diversification in this paper takes place at the individual company level, although they both can use the same set of measures.

Diversification is a multidimensional concept. Numerous studies on diversification at the individual company level have been published over the past decades (e.g. Jacquemin and Berry 1979, Palepu 1985, Chang and Thomas 1989, Chang 1996, Pandya and Rao 1998, Palich et al. 2000, Wiersema and Bowen 2008, Kim and Reinschmidt 2011b, Kang 2013, Su and Tsang 2015) with various diversification measures. Entropy was first applied to the assessment of diversification by Shannon (1948). It has the mathematical advantages that the measure can be divided into additive elements that contribute to the total index and that it accounts better for low levels of diversification compared to other measures (e.g. concentration ratio only considers top 4 
or 8 business sectors) (Jacquemin and Berry 1979, Choi and Russell 2005). Researchers have so far been largely intended to adopt entropy as a measure of a firm's diversification due to its more validity than the other measures (Hoskisson et al. 1993). The entropy measure as shown in eq. [1] can be used to develop a firm's diversity index (DI):

$$
\text { Entropy }=\sum_{i=1}^{N} p i \times \ln \frac{1}{p i} \quad \text { eq. [1] }
$$

Where $p i$ is the share of each product $i$ 's contribution to the firm's total mix; $N$ is the total sectors, and the natural logarithm of the inverse of the sales is the weight given to each sector. The DI is calculated as follows:

$$
\mathrm{DI}=\text { Entropy } / \ln (\mathrm{N})=\left(\sum_{i=1}^{N} p i \times \ln \frac{1}{p i}\right) / \ln (N)
$$

It can be seen from eq. [2] that the DI is a normalised entropy, i.e. dividing the entropy by the maximum $\ln (\mathrm{N})$. Therefore, the range of DI is from 0 to 1 . When a firm's DI is larger, the level of diversification is higher, while when there is no diversification, the DI is 0 .

The research further develops the DI as shown in eq. [2] to measure ICCs' diversification in business sectors and geographical markets, as expressed in eq. [3] and eq. [4], respectively.

$$
D I_{b}=\left(\sum_{i=1}^{N} p i \times \ln \frac{1}{p i}\right) / \ln (N)
$$

Where $D I_{b}$ is a firm's diversity index in business sectors, $p i$ is the revenue share of the $i$ th construction market sector in the firm's international revenues, and $N$ is the number of construction market sectors plus 1. It is because that most construction firms in the sample have non-contracting businesses, small though, and they are treat as one sector here. Nine construction business sectors are classified by the ENR, therefore, the possible business sectors of a firm totalled to $10(N=10)$.

$$
D I_{g}=\left(\sum_{j=1}^{M} p j \times \ln \frac{1}{p j}\right) / \ln (M)
$$


Where $D I_{g}$ is a firm's diversity index in geographical markets, $p j$ is the revenue share of the $j$ th geographical market in the firm's international revenues, and $M$ is the number of regional markets. As rehearsed above, six geographical markets are adopted, therefore, $M=6$.

\section{Analysis, results, and findings}

$H_{1}$ : International construction companies (ICCs) present different strategic groups in adopting diversification strategies in the international construction market.

Cluster analysis is most frequently employed as a classification tool to divide subjects into groups (clusters) that are meaningful and useful (Punj and Stewart 1983). Based on their diversity indexes in business sectors $\left(\mathrm{DI}_{\mathrm{b}}\right)$ and geographic market $\left(\mathrm{DI}_{\mathrm{g}}\right)$, the ICCs are categorised into several groups using statistical cluster analysis. $K$-means clustering methods is applied in the analysis by using $R$, a popular, open-source statistical software tool. The results are shown in Table 1 and Fig. 2. Ideally a cluster should have the properties of internal cohesion and external

separation, thus the Between Sum of Squares (BSS)/ Total Sum of Squares (TSS) ratio should approach 1. The BSS/TSS ratio of 74.4\% (0.744) as shown in Table 1 indicates a relatively good cluster classification.

$$
\begin{aligned}
& <<\text { Insert Table } 1 \text { here }>> \\
& <<\text { Insert Fig. } 2 \text { here }>>
\end{aligned}
$$

Four clusters are identified with the cluster sizes of 146, 124, 131, and 80, respectively. Cluster 1 includes ICCs with low DI (less diversifying in business sectors); Cluster 2 ICCs more 
preferring to diversify into business sectors than geographical markets; Cluster 3 ICCs with high level of $\mathrm{DI}_{\mathrm{b}}$ (more diversifying in business sectors); and Cluster 4 ICCs with high level of $\mathrm{DI}_{\mathrm{g}}$ (more diversifying in geographical markets). $H_{l}$ is supported by the results, which resonate with the concept of strategic group (Hunt 1972). Different groups of ICCs do adopt different diversification strategies in the international market.

Noteworthy, some ICCs in Cluster 1 possess high DIg but never diversify in the business sectors. These companies diversify into different regions but focus on one business line, in particular the industrial process/petroleum (IPP) sector. It seems that the heterogeneity (e.g. technologies, market operations) of IPP successfully prevents the potential entry/threat from outsiders to edge into this lubricated sector. Cluster 2 presents the opposite side that companies with high $\mathrm{DI}_{\mathrm{b}}$ seldom diversify in geographical markets. Most of them operate in their own home regions. Clusters 3 and 4 give the picture of ICCs diversifying significantly in both geographical regions and business sectors. These firms, as to be shown soon, are mainly large firms possessing abundant resources that allows them to diversify into a new business sector and into a new geographic market.

$\mathrm{H}_{2}$ : ICCs with larger firm sizes are likely more diversified than their smaller counterparts in the international construction market.

ICCs are further analysed to show the diversification patterns, which are visualised in Fig. 3. In the new exhibit, each point represents one observation of an ICC in a year. The size of the symbols represents the volume of international revenues received by the ICCs.

$<<$ Insert Fig. 3 here〉> 
Fig. 3 shows that the symbols with larger size mainly gather in the areas distant from the zero point. It illustrates that ICCs with larger international revenues prefer to diversify, either in business sectors, or in geographical markets, or in both. $H_{2}$ is thus supported.

A closer examination of the profiles of these large ICCs shows that they are basically two types: (a) operating in profitable sector such as IPP with high entry barriers and eager to duplicate their business into other regions; and (b) operating in low entry barrier sectors such as general building, transportation, or manufacturing facilities but having similar knowledge/capacity to diversify into other sectors. These findings thus echo with the ones in above section on $H_{1}$.

$H_{3}$ : ICCs are more likely to select geographical markets with shorter culture/institutional distance to diversify into.

Using the results shown in Fig. 2, ICCs are further analysed to show the diversification patterns, which are visualised in Figs 4 to 6. In these exhibits, each point still represents one observation of an ICC in a year, while the shapes of the symbols represent ICCs' origins. Six ICCs from North America are included in the analysis. As shown in Fig. 4, all the included North American ICCs operate in IPP business, implying that they are dominant in this highly specialised and lubricated sector. Meanwhile, they are able to diversify, mainly to Europe, which is a matured market with sophisticated institutional arrangements. Judging by culture/institutional distance between the home and host, they are close for market penetration. Otherwise, most of North American ICCs would choose the Middle East and Asia/Australia.

<< Insert Fig. 4 here〉> 
Twenty-five ICCs are from Europe, which are scattered into all the four clusters (see Fig 5). Most of ICCs from Europe located in Clusters 3 and 4 (with high $\mathrm{DI}_{\mathrm{b}}$ and high $\mathrm{DI}_{\mathrm{g}}$ ) are in relative large size. In addition to Europe as an indigenous market, their main oversea markets are in North America and Asia/ Australia, a diversification pattern similar to North American ICCs'.

$<$ Insert Fig. 5 here $>$

Eighteen ICCs from Asia and Australia are analysed. As shown in Fig. 6, they are mainly located in Clusters 1 and 3 but disperse geographically. Most of the ICCs from Asia/Australia prefer to operate in their own region. Noteworthy, ICCs from South Korea do business in IPP in the Middle East as their traditional market; ICCs from Japan operate in North America while their businesses are not limited to just one line. Due to the paucity of empirical data, Chinese contractors are not included in these analyses, although they are emerging rapidly in recent years in the international market. Previous studies (e.g. Low and Jiang 2003, Lu et al. 2009) reported that they preferred to work in Africa where they have a traditional tie and a strong 'government to government' (G2G) strategy, or in Southeast Asia where they have a culture link.

$<$ Insert Fig. 6 here $>$

The above analyses seemingly support $H_{3}$, which proposes culture/institutional distance does influences the entry or no-entry of ICCs to a new geographical market. However, contractors from the U.S. prefer to operate in the Middle East probably due to the foreign policies and priorities 
of the U.S. in the region. There is little previous theoretical discussion on political priorities' impact on the choice of international construction markets to enter. Researchers may find the OLI framework (Dunning 1979) providing more explanatory power to the diversification patterns in international construction market.

H4: ICCs diversify widely in either business sectors or geographic markets but not in both dimensions simultaneously.

Fig. 7 illustrates the average $\mathrm{DI}_{b}$ of the sample ICCs on a yearly basis ranging from 2001 to 2015. It reflects the overall longitudinal diversification patterns in business sectors. There is no clear trend of diversification but it seems that the average $\mathrm{DI}_{\mathrm{b}}$ is largely stabilised within the range 0.30 to 0.45 .

$<$ Insert Fig. 7 here >>

Fig. 8 shows the average $\mathrm{DI}_{\mathrm{g}}$ of the sample ICCs on a yearly basis ranging from 2005 to 2015. It is a reflection of the overall longitudinal diversity pattern in geographical markets. There is a moderate but apparent trend of increasing diversification (except $\mathrm{DI}_{\mathrm{g}}$ in 2015) in different geographical markets. With the steady growth of international construction business, ICCs enter or exit these regional markets to either achieve growth, or alleviate risks, or both. By combining the data analyses of the two dimensions together, $H_{4}$ is supported. The temptation is to say that venture into a new geographical market is risky already, there is no need to double the risks by simultaneously diversifying into a new business sector. 
$<<$ Insert Fig. 8 here >>

The findings from this section further reinforce the findings from testing $H_{l}$, which show ICCs only diversify in one dimension, either business sectors or geographic markets. At the first glance, some of the findings from this section are contradicting with those found in $H_{l}$, which

showed that ICCs, mainly larger ones, do diversify in both business sectors and geographic markets. However, readers are reminded that $H_{4}$ examines all the ICCs as a whole from a longitudinal perspective. The results from this section thus should be read in conjunction with previous ones to allow a holistic picture of diversification patterns to be painted.

\section{Discussion}

The rise of the global construction business and the fall of traditional trade barriers have attracted contractors to diversify into the international market place. By doing so, companies can meet market demands, and spread the risk of over reliance upon particular regional markets or business sectors. Measuring and mapping diversification patterns will possibly reveal diversification strategies that lead to the identified patterns. ICCs do show some variability in diversification patterns in the international construction market. It is a clear presentation that larger ICCs are more diversified than their smaller counterparts in both business sectors and geographical markets. Firms' excessive and scalable resources, together with their profit-seeking motivations, are the major explanations for their diversification strategies (Ansoff 1957, Lowe and Teece 2001, Arasti et al., 2010).

The analyses in this paper also discover two interesting groups of ICCs, which only diversify either in the business sectors or in the geographical markets. This can be explained by 
several reasons. Firstly, if possible, ICCs would like to operate in their own regions or regions with similar cultural/institutional environment. Smaller cultural/institutional distance could reduce the risk for diversification, ICCs thus naturally choose these regions to diversify. For example, some European companies, e.g. Strabag SE and Royal Bam Group, only focus on the European markets and their businesses are mainly related to general building and transportation. The Australian company CIMIC Inc. (former name was Leighton Holdings Ltd.) only focus on Asia/Australia although its businesses are quite diversified. Besides, political preferential policies between countries may help lower the entry barriers and promote diversification in geographical markets. Secondly, market demand motivates ICCs to diversify to different regions such as the oil-rich Middle East and Africa. This provides good opportunities for the ICCs to do businesses in this specific sector. Thirdly, excessive resources and core competence play an important role for business diversification. For the ICCs which do the traditional construction, such as general building, transportation, or manufacturing facilities, they may diversify significantly since they may share the same resources or technologies for the related diversification. However, other business sectors, like the IPP sector, which need sophisticated technical 'know-how', present a different pattern. Most of the contractors operating in this sector only diversify to other geographical markets by sticking to the same business. Based on all these, the temptation is to say that venture into a new geographical market is risky already, there is no need to double the risks by simultaneously diversifying into a new business sector.

The analyses in this paper provide valuable empirical evidence to substantiating various theories relating to firm diversification. Firm diversification is one of the most theoretically debated phenomenon; theories range from Ansoff (1957) in early days to Panzar and Willig's (1977) economies of scope and scale, Porter's (1980, 1985) competitive advantage and 
competitive strategies, Dunning's (1979) ownership, location and internalization (OLI) theory, and Barney's (1991) resource-based views (RBV), and the cultural or institutional explanations of entry modes (e.g. Hofstede 1984, Kogut and Singh 1988, Bae and Salomon 2010) in more recent times, all have been explored with a view to explaining the phenomenon of diversification. Construction business, in particular in an international scale, provides an intriguing test bed for testing these theories; some are more held than others. The paper, hopefully, can trigger more theoretical debates in explaining why and how an ICC diversifies.

The analyses in this paper portray a macro picture of diversification patterns of ICCs as a group or different groups (e.g. sizes, or origins of countries). It is unclear whether the patterns are the result of a natural selection by ICCs or the result of their planned diversification strategies. Traditionally, ICCs diversified through natural growth. However, in recent years, some ICCs, in particular the top ones, have adopted aggressive M\&A strategies (Lu 2014, Lu et al. 2013). Selecting an appropriate diversification strategy is a perpetual challenge to any firm, ICCs have no exception. Although the macro picture cannot sufficiently describe the diversification on a micro scale by individual ICCs, the diversification patterns discovered in this study provides a good starting point to examine meaningful arguments (e.g. the diversification strategies leading to the patterns, the reasons leading to different strategic groups, or the business performance implications of the diversification patterns) using empirical data and statistical methods.

\section{Conclusion}

This research investigated diversification in international construction business based on the diversity index (DI) calculated in business sectors and geographical markets. It is found that international construction companies (ICCs) as a whole have been actively diversifying into 
different geographical markets but relatively stable in staying in their comfort zone of business sectors over the past years. Digging into the ICCs, it revealed that they presented different strategic groups in adopting diversification strategies; some diversify only in business sectors, some only in geographical markets, while others are aggressive in both. Larger ICCs, with their abundant resources and using their acquired experience, are more diverse in both business sectors and geographical regions than their smaller counterparts. Most of the ICCs tend to operate in their own regions or diversify into regions with similar cultural or institutional environment to avoid risks while enjoying the new market opportunities in these regions.

This study empirically tested the various theories relating to business diversification. The international construction business is an intriguing test bed for diversification theories. Although it would be too ambitious for a single paper like this to test all the relevant theories, the study developed some useful empirical evidence. The theories have varying explanatory power to explain companies' diversification in the international construction market; some theories are more held than others, but none seems monolithic in explaining the phenomemon. This study provides a good starting point to furthering theoretical debates in explaining why and how an ICC diversify.

This study portrayed a macro picture of ICCs' diversification patterns and their trajectories over time. The DI measured can be further utilised as a variable to examine the nexus between diversification strategy and business performance using quantitative methods. However, understanding the diversification strategies of individual ICCs at a micro level can be better achieved by using qualitative research methods such as case studies or interviews. These are recommended as future studies.

The study is not free of limitations. The availability of data for examining geographical diversification is not as good as the data for market sector diversification, thus the overall number 
of samples is limited. Only 49 ICCs were selected as a sample. Secondly, the selected ICCs are mostly large companies, although a closer examination found varying company sizes in terms of annual revenues. Therefore, when discussing 'larger' or 'smaller' ICCs, it is necessary to be mindful of the relativeness of company size. Those small ICCs in absolute terms are not examined in this study owing to the erratic data available for the analyses.

\section{References}

Abdul-aziz, and Abdul-Rashid., 1994. Global strategies: a comparison between Japanese and American construction firms. Construction Management and Economics, 12(6), 473-484.

Anand, J., and Singh, H., 1997. Asset redeployment, acquisitions and corporate strategy in declining industries. Strategic Management Journal, 18(S1), 99-118.

Ansoff, H. I., 1957. Strategies for diversification. Harvard Business Review, 35(5), 113-124.

Arasti, M.R., Khaleghi, M. and Noori, J., 2010. The linkage of technology strategy and overall strategy of multi business diversified groups: Literature review and theoritical framework. In: Technology Management for Global Economic Growth(PICMET), 18 July 2010: IEEE, 1-12.

Bae, J.H. and Salomon, R., 2010. Institutional distance in international business research. In Devinney, T., Pedersen, T., Tihanyi, L. eds. The past, present and future of international business \& management, Emerald Group Publishing Limited, 327-349.

Barney, J., 1991. Firm resources and sustained competitive advantage. Journal of Management, 17(1), 99-120.

Bird, K., 1999. Concentration in Indonesia Manufacturing, 1975-93. Bulletin of Indonesian Economic Studies, 35(1), 43-73.

Booz, A., Allen, J., and Hamilton Inc., 1985. Diversification, a survey of European chief executives- Executive Summary, New York, NY.

Capar, N., and Kotabe, M., 2003. The relationship between international diversification and performance in service firms. Journal of International Business Studies, 34(4), 345-355. 
Chang, S. J., 1996. An evolutionary perspective on diversification and corporate restructuring: Entry, exit, and economic performance during 1981-89. Strategic Management Journal, 17(8), 587-611.

Chang, Y., and Thomas, H., 1989. The impact of diversification strategy on risk-return performance. Strategic Management Journal, 10(3), 271-284.

Chen, C., and Messner, J. I., 2005. An investigation of Chinese BOT projects in water supply: a comparative perspective. Construction Management and Economics, 23(9), 913-925.

Choi, J., and Russell, J. S., 2005. Long- Term Entropy and Profitability Change of United States Public Construction Firms. Journal of Management in Engineering, 21(1), 17-26.

Coase, R. H., 1937. The nature of the firm. Economica, 4(16), 386-405.

Dainty, A., Moore, D., and Murray, M., 2007. Communication in Construction: Theory and Practice, Routledge.

Dunning, J.H., 1979. Explaining changing patterns of international production: in defence of the eclectic theory. Oxford Bulletin of Economics and Statistics, 41(4), 269-295.

Global Construction Perspectives and Oxford Economics, 2015. Global construction 2030: $a$ global forecast for the construction industry to 2030. [online]London. Avaiable at: https://policy.ciob.org/wpcontent/uploads/2016/06/GlobalConstruction2030_ExecutiveSummary_CIOB.pdf. [Accessed Feb. 20 ${ }^{\text {th }}$, 2017]

Hillebrandt, P. M., 2000. Economic Theory and the Construction Industry, Macmillan London.

Hitt, M. A., Hoskisson, R. E., and Kim, H., 1997. International diversification: Effects on innovation and firm performance in product-diversified firms. Academy of Management Journal, 40(4), 767-798.

Hofstede, G., 1984. Culture's Consequences: International Differences in Work-Related Values (2nd ed.). Beverly Hills CA: SAGE Publications

Hoskisson, R. E., Hitt, M. A., Johnson, R. A., and Moesel, D. D., 1993. Construct validity of an objective (entropy) categorical measure of diversification strategy. Strategic Management Journal, 14(3), 215-235.

Hunt, M. S., 1972. Competition in the Major Home Appliance Industry 1960-1970, Unpublished doctoral dissertation, Harvard University. 
Jacquemin, A. P., and Berry, C. H., 1979. Entropy measure of diversification and corporate growth. The Journal of Industrial Economics, 27(4), 359-369.

Jewell, C., 2011. A typology of construction professional service firms: a consulting engineering perspective. Thesis ( $\mathrm{PhD})$, University of Reading.

Jewell, C. and Flanagan, R., 2012. Measuring construction professional services exports: a case for change. Building Research and Information, 40 (3). 337-347.

Jewell, C., Flanagan, R., and Anaç, C., 2010. Understanding UK construction professional services exports: definitions and characteristics. Construction Management and Economics, 28(3), 231-239.

Jewell, C., Flanagan, R., and Lu, W., 2014. The dilemma of scope and scale for construction professional service firms. Construction Management and Economics, 32(5), 473-486.

Kale, S., and Arditi, D., 2002. Competitive positioning in United States construction industry. Journal of Construction Engineering and Management, 128(3), 238-247.

Kang, J., 2013. The relationship between corporate diversification and corporate social performance. Strategic Management Journal, 34(1), 94-109.

Kim, H., and Reinschmidt, K., 2011a. Association of risk attitude with market diversification in the construction business. Journal of Management in Engineering, 27(2), 66-74

Kim, H., and Reinschmidt, K., 2011b. Diversification by the largest US contractors. Canadian Journal of Civil Engineering, 38(7), 800-810.

Kogut, B., and Singh, H., 1988. The effect of national culture on the choice of entry mode. Journal of international business studies, 19(3), 411-432.

Liu, Chunlu and Zhu, Ruixue, 2017. Measuing output structures of multinational construction industries using the World Input-Output Database. International Journal of Construction Management, 17(1), 1-12.

Locket, A., Wiklund, J., Davidsson, P., Sourafel, G., 2009. Organic and acquisitive growth. Journal of Management Studies, 2(1), 1-52.

Low, S. P., and Jiang, H., 2003. Internationalization of Chinese construction enterprises. Journal of Construction Engineering and Management, 129(6), 589-598.

Lowe, R. A., and Teece, D. J., 2001. Diversification and economies of scope. In: N. J. S. B. Baltes, eds. International Encyclopedia of the Social \& Behavioral Sciences, Oxford, Pergamon, 3574-3578. 
Løwendahl, B., 2005. Strategic management of professional service firms. Copenhagen Business School Press DK.

Lu, W., 2014. Reliability of Engineering News- Record international construction data. Construction Management and Economics, 32(10), 968-982.

Lu, W., Li, H., Shen, L., and Huang, T., 2009. Strengths, weaknesses, opportunities, and threats analysis of Chinese construction companies in the global market. Journal of Management in Engineering, 25(4), 166-176.

Lu, W., Ye, K., Flanagan, R., and Jewell, C., 2013. Developing construction professional services in the international market: SWOT analysis of China. Journal of Management in Engineering, 29(3), 302-313.

Lu, W., Ye, K., Flanagan, R., and Jewell, C., 2014. Nexus between contracting and construction professional service businesses: empirical evidence from international market. Journal of Construction Engineering and Management, 140(2), 04013049.

Marshall, B.R., Nguyen, N.H. and Visaltanachoti, N., 2015. Frontier market transaction costs and diversification. Journal of Financial Markets, 24, 1-24.

McCloughan, P., 2004. Construction sector concentration: evidence from Britain. Construction Management and Economics, 22(9), 979-990.

Ngowi, A. B., Pienaar, E., Talukhaba, A., and Mbachu, J., 2005. The globalisation of the construction industry - A review, Building and Environment, 40(1), 135-141.

Palepu, K. 1985. Diversification strategy, profit performance and the entropy measure. Strategic Management Journal, 6(3), 239-255.

Palich, L., Cardinal, L., Miller, C., 2000. Curvilinearity in the diversification-performance linkage: an examination of over three decades of research. Strategic Management Journal, 21(2), 155-174.

Pandya, A. M., and Rao, N. V., 1998. Diversification and firm performance: an empirical evaluation. Journal of Financial and Strategic Decisions, 11(2), 67-81.

Panzar, J. C., and Willig, R. D., 1977. Economies of scale in multi-output production. The Quarterly Journal of Economics, 91(3), 481-493.

Panzar, J. C., and Willig, R. D., 1981. Economies of Scope. American Economic Review, 71, 268272. 
Pearce, D., 2003. Environment and business: socially responsible but privately profitable? In: J. Hirst. Eds. The Challenge of Change : Fifty Years of Business Economics, Profile Books, London, 54-65.

Penrose, E.T., 1959. The Theory of the Growth of the Firm, $3^{\text {rd }}$ ed. Oxford University Press, Oxford, UK.

Porter, M. E., 1980. Competitive Strategies: Techniques for Analysing Industries and Competitors. New York, Free Press.

Porter, M. E., 1985. The Competitive Advantages: Creating and Sustaining Superior Performance. New York, Free Press.

Punj, G., and Stewart, D. W., 1983. Cluster analysis in marketing research: Review and suggestions for application. Journal of marketing research, 134-148.

Ross, Stephen A., Randolph Westerfield, and Jeffrey F. Jaffe., 1993. Corporate finance. $3^{\text {rd }}$ ed. Homewood, IL: Irwin.

Rowe, W. G., and Wright, P. M. 1997. Related and unrelated diversification and their effect on human resource management controls. Strategic management journal, 329-338.

Rowland, P. F., 1999. Transaction costs and international portfolio diversification. Journal of International Economics, 49(1), 145-170.

Rubinstein, M., 2002. Markowitz's “Portfolio Selection”: A Fifty-Year Retrospective. The Journal of Finance, 57(3), 1041-1045.

Seymour, H., 1987. The multinational construction industry. Routledge.

Shannon, C. E., 1948. A mathematical theory of communication. Bell System Technical Journal, 27(3), 379-423.

Su, W., and Tsang, E. W., 2015. Product diversification and financial performance: The moderating role of secondary stakeholders. Academy of Management Journal, 58(4), 11281148.

Wiersema, M. and Bowen, H., 2008. Corporate diversification: The impact of foreign competition, industry globalisation, and product diversification. Strategic Management Journal, 29(2), $115-132$

Williamson, O.E., 1991. Strategizing, economizing, and economic organization. Strategic Management Journal, 12(S2), 75-94.

Wrigley, L. 1970. Diversification and divisional autonomy. DBA thesis, Harvard Business School. 
WTO., 1998. Construction and related engineering services: Background, Note by Secretariat. S/C/W/38 Geneva, 8 June 1998.

Ye, K., Lu, W., and Jiang, W., 2009. Concentration in the international construction market. Construction Management and Economics, 27(12), 1197-1207. 


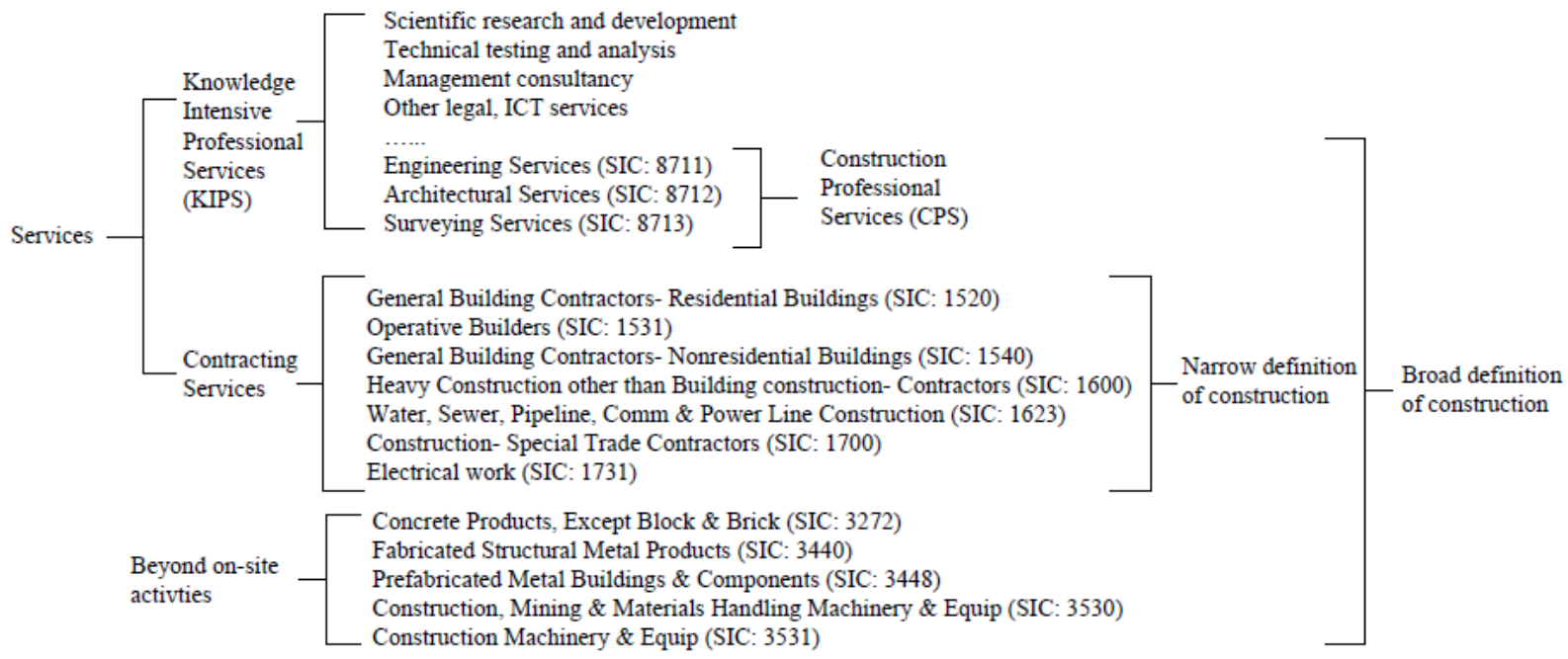

Fig. 1: Industrial classification of construction businesses for understanding related and unrelated diversification 


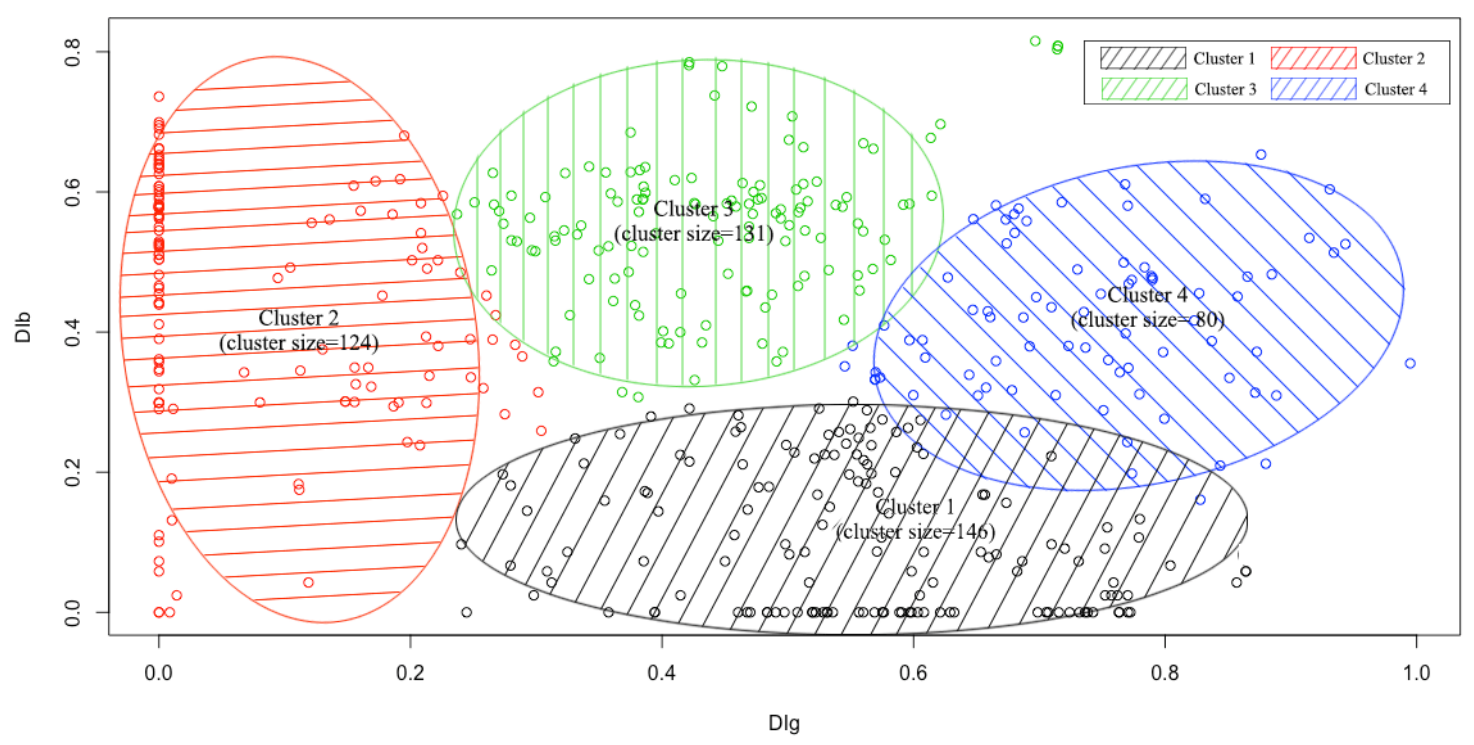

Fig. 2: Results of cluster analysis based on $\mathrm{DI}_{\mathrm{b}}$ and $\mathrm{DI}_{\mathrm{g}}$ 


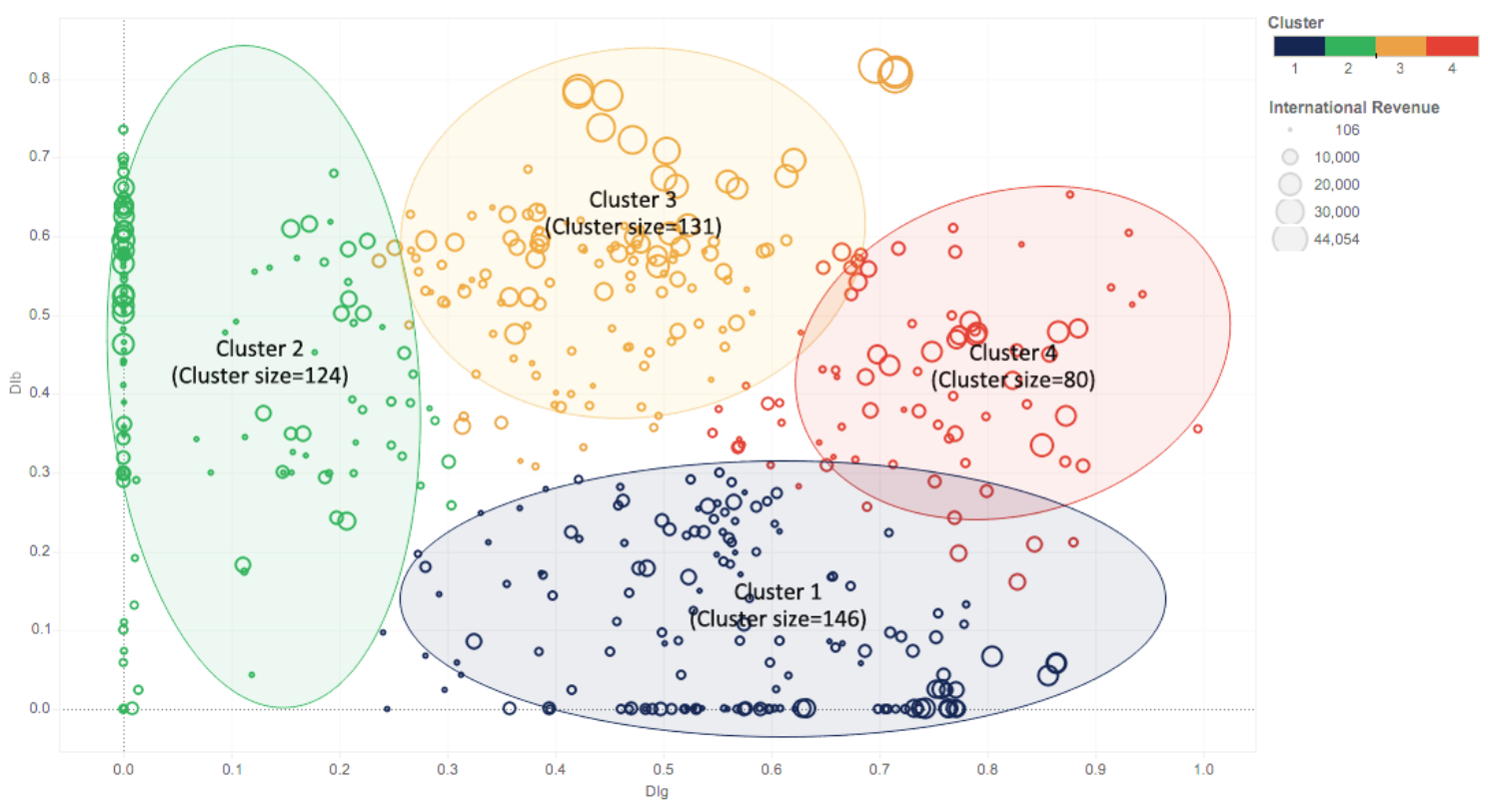

Fig.3: Overall diversification pattern for international construction companies (ICCs) 


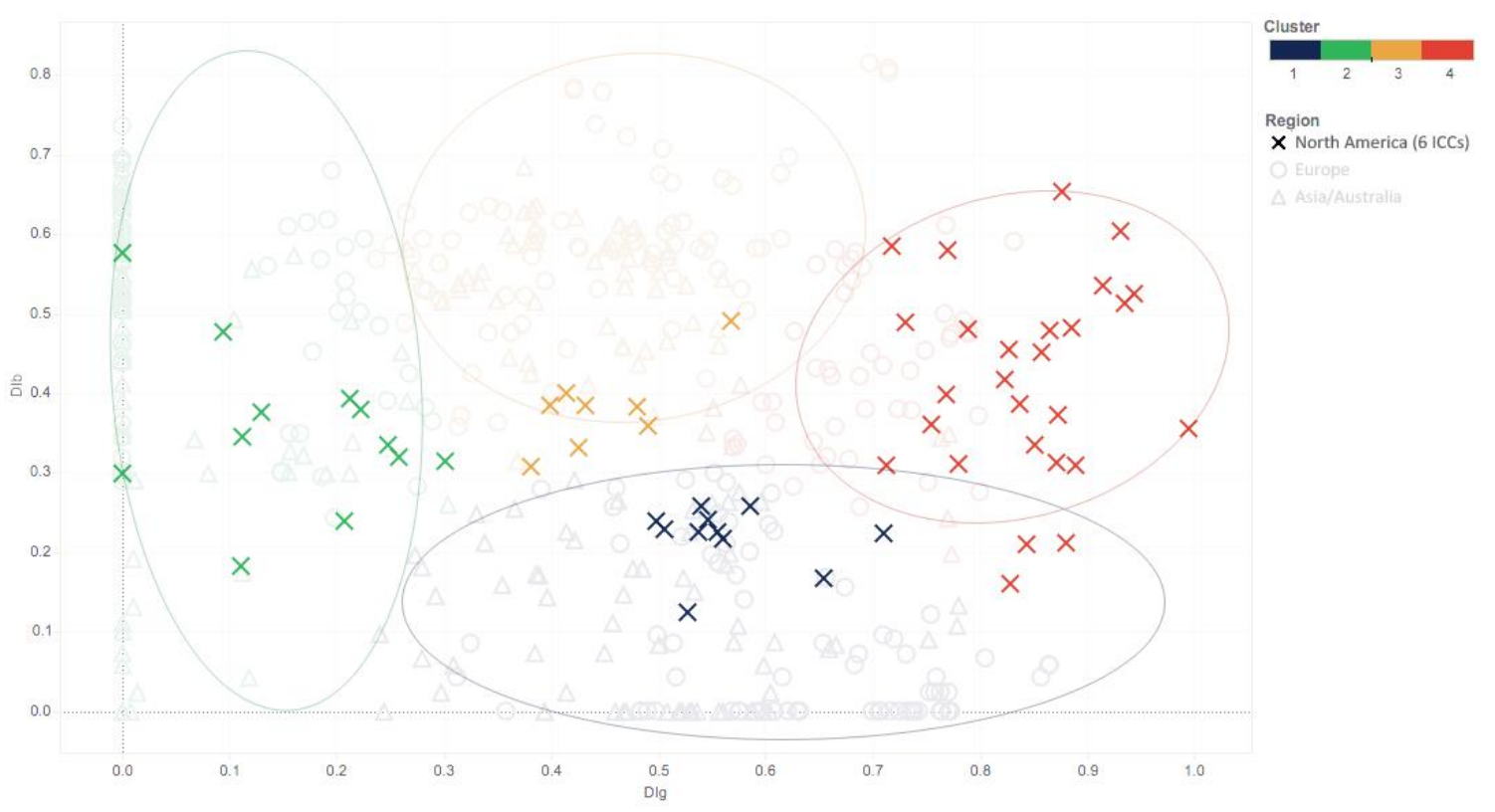

Fig.4: Diversification pattern for ICCs from North America 


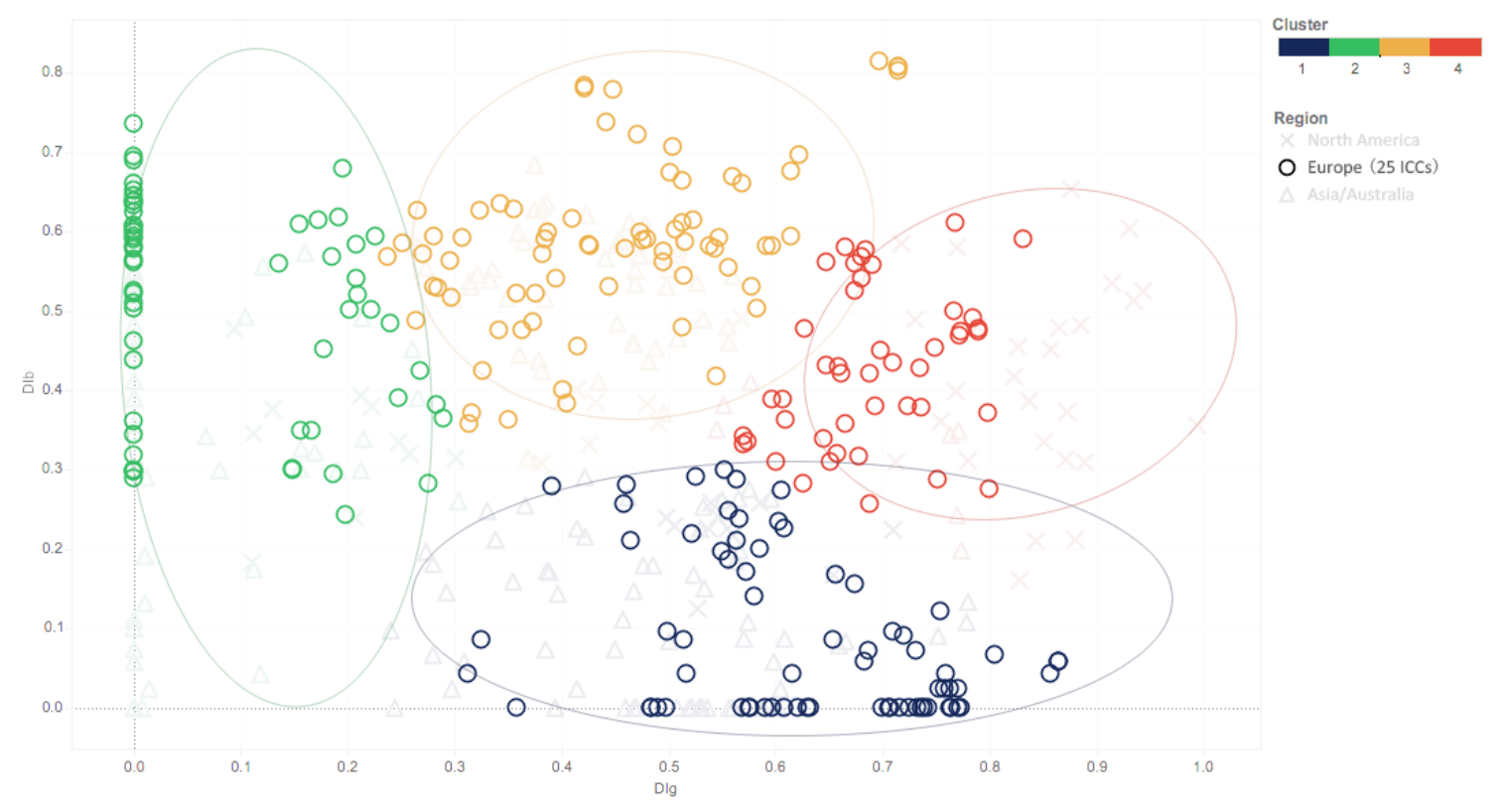

Fig.5: Diversification pattern for ICCs from Europe 


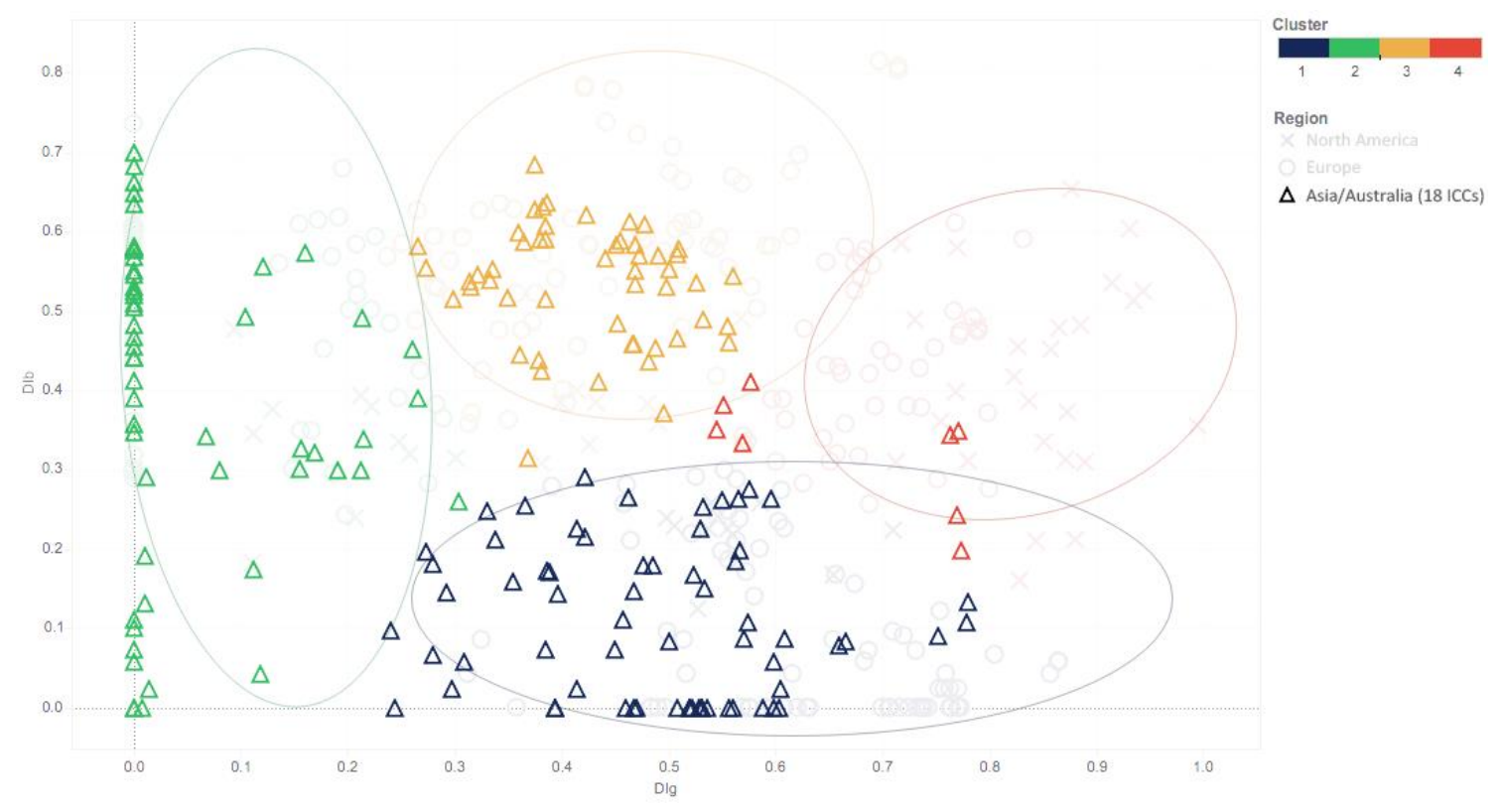

Fig.6: Diversification pattern for ICCs from Asia and Australia 


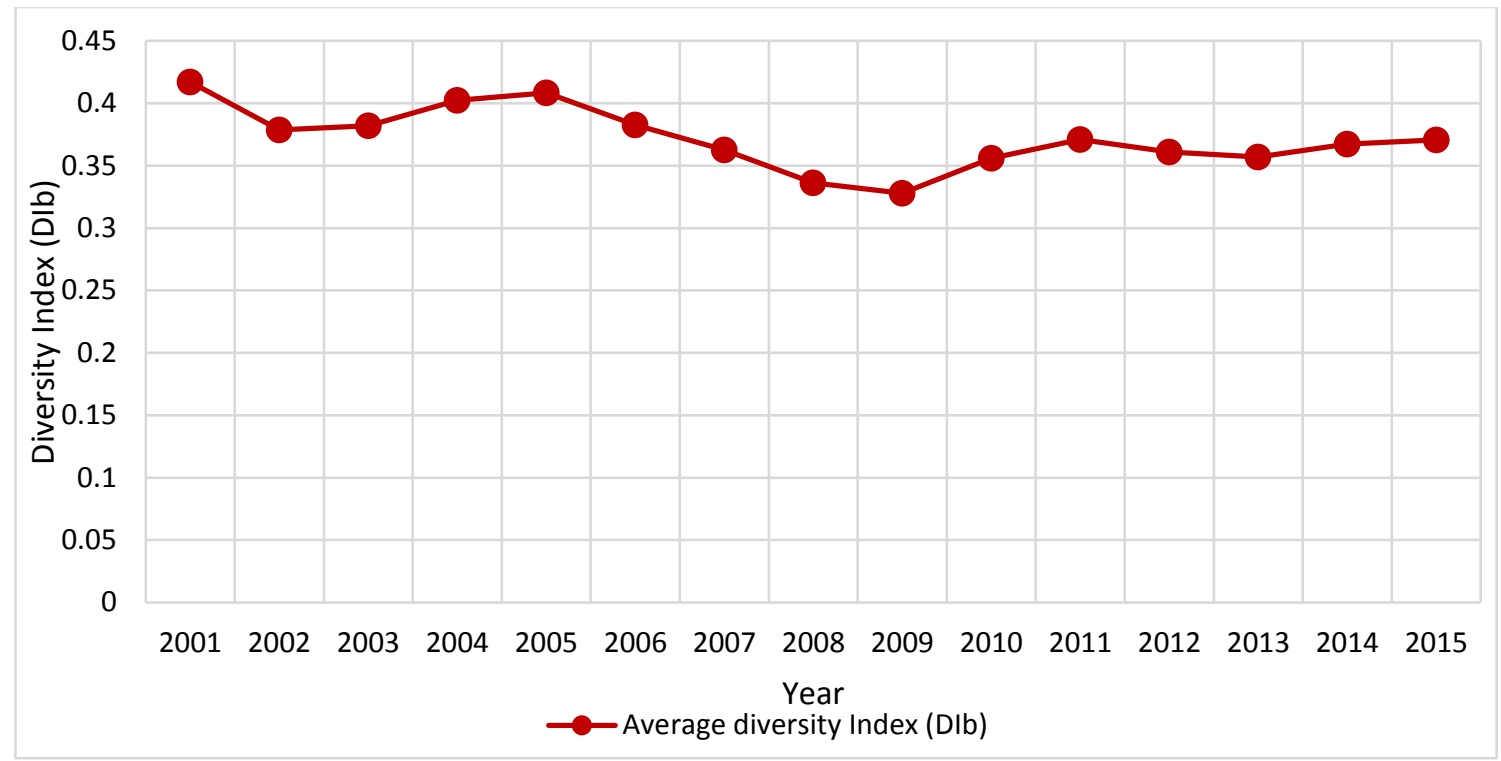

Fig.7: Averages of business diversity index $\left(\mathrm{DI}_{\mathrm{b}}\right)$ of all the sample ICCs (2001-2015) 


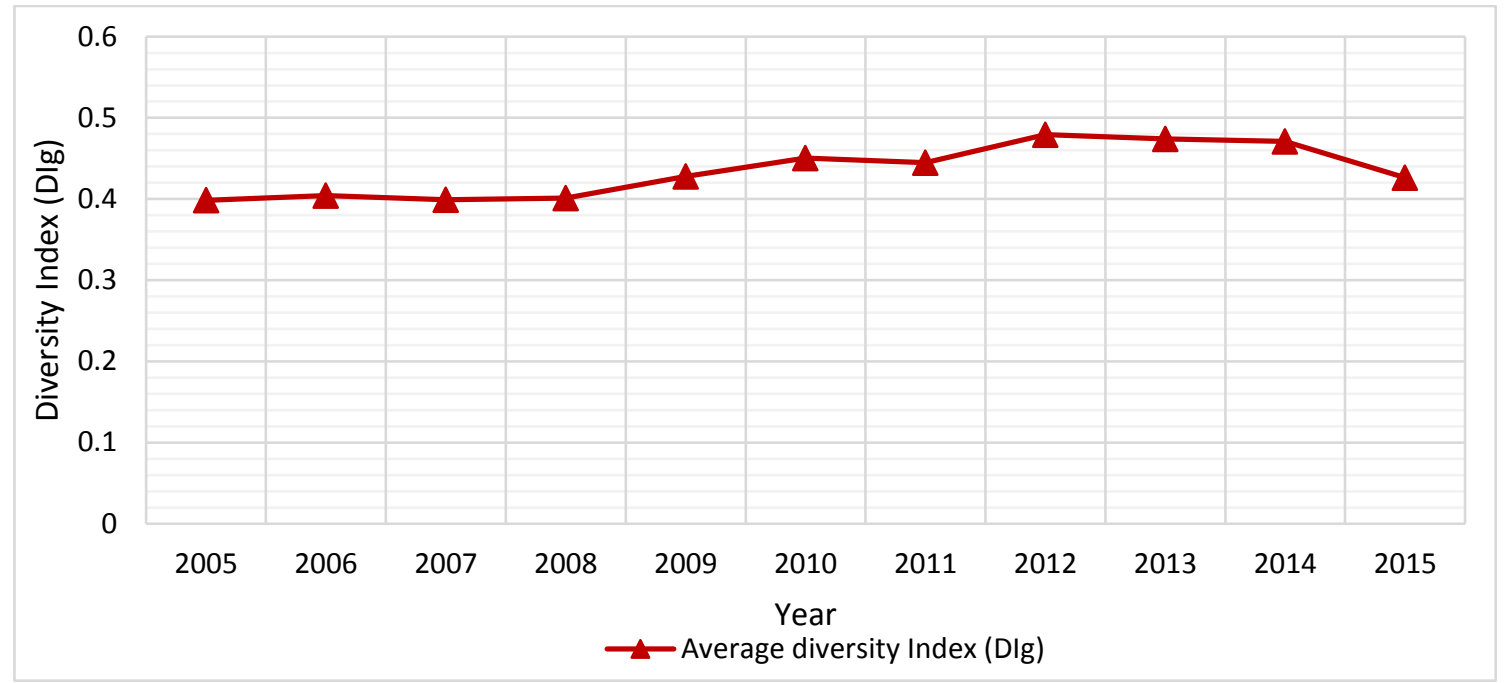

Fig. 8: Averages of geographical diversity index (DIg) of all the sample ICCs (2005-2015) 
Table 1 Summary in results of k-means clustering analysis

\begin{tabular}{lccccc}
\hline & Cluster 1 & Cluster 2 & Cluster 3 & Cluster 4 \\
\hline Cluster sizes & & 146 & 124 & 131 & 80 \\
\hline $\begin{array}{l}\text { Cluster } \\
\text { centers }\end{array}$ & $\mathbf{D I}_{\mathbf{b}}$ & 0.1072 & 0.4360 & 0.5528 & 0.4140 \\
\cline { 2 - 6 } $\begin{array}{l}\text { Within cluster sum of } \\
\text { squares }\end{array}$ & 0.5587 & 0.0802 & 0.4391 & 0.7394 \\
\hline between_SS $*$ / total_SS $=\mathbf{7 4 . 4} \%$ & 4.2384 & 5.0226 & 2.8272 & 1.8054 \\
\hline
\end{tabular}

* SS stands for Sum of Squares 